\title{
Catecholaminergic Fiber Innervation of the Vocal Motor System Is Intrasexually Dimorphic in a Teleost with Alternative Reproductive Tactics
}

\author{
Zachary N. Ghahramani ${ }^{\mathrm{a}, \mathrm{c}}$ Miky Timothy ${ }^{\mathrm{a}}$ Gurpreet Kaur $^{\mathrm{a}}$ \\ Michelle Gorbonosov $^{a}$ Alena Chernenko ${ }^{a}$ Paul M. Forlano ${ }^{\text {a-e }}$ \\ ${ }^{\mathrm{a}}$ Department of Biology and ${ }^{\mathrm{b}}$ Aquatic Research and Environmental Assessment Center, Brooklyn College, Brooklyn, \\ N.Y., USA Doctoral Subprograms in ${ }^{\mathrm{C} E c o l o g y, ~ E v o l u t i o n a r y ~ B i o l o g y ~ a n d ~ B e h a v i o r, ~}{ }^{\mathrm{d}}$ Neuroscience and ${ }^{\mathrm{B}}$ Behavioral \\ and Cognitive Neuroscience, The Graduate Center, City University of New York, New York, N.Y., USA
}

\section{Key Words}

Teleost $\cdot$ Dopamine $\cdot$ Noradrenaline $\cdot$ Catecholamine . Vocal motor - Alternative reproductive tactics · Posterior tuberculum · Locus coeruleus · Preoptic area

\begin{abstract}
Catecholamines, which include the neurotransmitters dopamine and noradrenaline, are known modulators of sensorimotor function, reproduction, and sexually motivated behaviors across vertebrates, including vocal-acoustic communication. Recently, we demonstrated robust catecholaminergic (CA) innervation throughout the vocal motor system in the plainfin midshipman fish Porichthys notatus, a seasonal breeding marine teleost that produces vocal signals for social communication. There are 2 distinct male reproductive morphs in this species: type I males establish nests and court females with a long-duration advertisement call, while type II males sneak spawn to steal fertilizations from type I males. Like females, type II males can only produce brief, agonistic, grunt type vocalizations. Here, we tested the hypothesis that intrasexual differences in the number of CA neurons and their fiber innervation patterns throughout the vocal motor pathway may provide neural substrates underlying divergence in reproductive behavior between morphs. We employed immunofluorescence (-ir) histochemistry to measure
\end{abstract}

tyrosine hydroxylase $(\mathrm{TH}$; a rate-limiting enzyme in catecholamine synthesis) neuron numbers in several forebrain and hindbrain nuclei as well as TH-ir fiber innervation throughout the vocal pathway in type I and type II males collected from nests during the summer reproductive season. After controlling for differences in body size, only one group of CA neurons displayed an unequivocal difference between male morphs: the extraventricular vagal-associated TH-ir neurons, located just lateral to the dimorphic vocal motor nucleus (VMN), were significantly greater in number in type II males. In addition, type II males exhibited greater $\mathrm{TH}$-ir fiber density within the $\mathrm{VMN}$ and greater numbers of $\mathrm{TH}$-ir varicosities with putative contacts on vocal motor neurons. This strong inverse relationship between the predominant vocal morphotype and the CA innervation of vocal motor neurons suggests that catecholamines may function to inhibit vocal output in midshipman. These findings support catecholamines as direct modulators of vocal behavior, and differential CA input appears reflective of social and reproductive behavioral divergence between male midshipman morphs.

(c) 2015 S. Karger AG, Basel

Z.N. Ghahramani, M. Timothy, A. Chernenko and P.M. Forlano are members of the J.B. Johnston Club for Evolutionary Neuroscience.

\section{KARGER 125}

(c) 2015 S. Karger AG, Base

$0006-8977 / 15 / 0862-0131 \$ 39.50 / 0$

E-Mail karger@karger.com

www.karger.com/bbe
Zachary N. Ghahramani

c/o Forlano Lab, Department of Biology, Brooklyn College

2900 Bedford Ave

Brooklyn, NY 11210 (USA)

E-Mail zghahramani@gradcenter.cuny.edu 


\section{Introduction}

Batrachoidid fishes (midshipman and toadfish) possess a straightforward repertoire of vocalizations complemented by vocal circuitry that is evolutionarily conserved [Goodson and Bass, 2002; Bass et al., 2008; Bass, 2014]. The plainfin midshipman fish Porichthys notatus is a well-studied neuroethological model for investigating the neural and hormonal mechanisms underlying vertebrate vocal behavior. This is due to the fact that production and recognition of social-acoustic signals are critical to reproduction in this species. In the summer breeding season at sites along the western coast of North America, males vocally court females from under rocky intertidal nests and females localize males by following their call. There are two distinct reproductive male morphs that follow divergent developmental trajectories with corresponding alternative reproductive tactics: type I males defend a nest and vocally court females, while type II males do neither but instead sneak spawn in competition with type I males [Brantley and Bass, 1994; Bass, 1996]. Type II males also reach sexual maturity earlier and share a multitude of biochemical, hormonal, morphological, and behavioral similarities to females that are different from type I males [Bass et al., 1996; Goodson and Bass, 2000; Remage-Healey and Bass, 2007; Bass and Forlano, 2008; Arterbery et al., 2010a, b].

Batrachoidid fishes possess an expansive vocal motor network, including a rhythmically firing vocal pattern generator (VPG), located in the caudal hindbrain-rostral spinal cord [Bass et al., 2008; Chagnaud et al., 2011; Bass, 2014]. Preoptic and hypothalamic ventral (vT) and anterior (AT) tuberal nuclei, which are reciprocally connected to the ventral telencephalon, project to the midbrain periaqueductal gray (PAG) and paratoral tegmentum (PTT), which in turn innervate the vocal prepacemaker nucleus, the most rostral part of the VPG [Goodson and Bass, 2002; Kittelberger and Bass, 2013]. The vocal prepacemaker nucleus encodes the duration of the call, while its efferent target, i.e. vocal pacemaker neurons, encodes the call frequency (pulse repetition rate) that is delivered by the vocal motor nucleus (VMN) [Chagnaud et al., 2011]. VMN axons exit the brain by way of occipital nerve roots to sound-producing vocal muscle attached to the sides of the swim bladder [Bass et al., 1994]. Type I males are the only morphotype capable of producing agonistic growls and the long duration advertisement call ('hum') that is attractive to the female, whereas type II males and females can only produce short-duration agonistic grunts [Bass, 1996; Bass and McKibben, 2003; McIver et al., 2014].
Well-established sexual polymorphisms in the midshipman hindbrain-spinal vocal circuitry are related to divergence of male vocal behavior. Type I males have larger vocal muscles in addition to a larger-volume VMN with larger motor neurons compared to type II males and females [Bass and Baker, 1990; Bass et al., 1996; Bass and Forlano, 2008]. Despite their relatively small body size and minimal, female-like vocal muscle, type II males possess a testes-to-body weight ratio that is 9 times greater than that of type I males [Bass, 1996].

Like songbirds [Mello et al., 1998; Appeltants et al., 2001, 2002a, b; Castelino and Ball, 2005; Hara et al., 2007], the vocal motor pathway in midshipman receives significant catecholaminergic (CA) input [Forlano et al., 2014; Goebrecht et al., 2014]. Tyrosine hydroxylase (TH), the rate-limiting enzyme in catecholamine synthesis, can be used as a marker for neurons that synthesize and release the neurotransmitters dopamine (DA) and noradrenaline (NA), known modulators of motivated vertebrate sociosexual behaviors [O'Connell and Hofmann, 2011; Riters, 2012; Kelly and Goodson, 2015]. Recent neuroanatomical studies support a role for catecholamines as modulators of social-acoustic behavior in midshipman. Using cFos-ir as a marker for neural activation, both TH immunoreactive (-ir) neurons in the diencephalic periventricular posterior tuberculum (TPp), known to be dopaminergic [Tay et al., 2011; Yamamoto and Vernier, 2011], and the noradrenergic locus coeruleus (LC) of type I males are preferentially responsive to conspecific advertisement calls compared to ambient noise [Petersen et al., 2013]. There is also seasonal variation in the density of $\mathrm{TH}$-ir fiber innervation throughout the central and peripheral auditory system of female midshipman related to reproductive state [Forlano et al., 2015]. However, relationships between TH-ir and circuitry underlying alternative male reproductive behavior are unexplored. Brain CA nuclei and fiber densities are known to be regulated by steroid hormones [Wilczynski et al., 2003; LeBlanc et al., 2007; Kabelik et al., 2011; Matragrano et al., 2013; Barth et al., 2015], and forebrain dopaminergic neurons in midshipman are located in areas replete with androgen and estrogen receptors and aromatase (estrogen synthase) [Forlano et al., 2001, 2005, 2010, 2014]. Importantly, steroid hormone profiles, estrogen receptor expression, and aromatase activity and expression are different between male morphs [Brantley et al., 1993; Schlinger et al., 1999; Forlano and Bass, 2005; Fergus and Bass, 2013], which may regulate morph differences in CA neuron number and/or their innervation patterns. 
Here, we tested the hypothesis that the numbers of CA neurons in key forebrain and hindbrain nuclei and CA fiber innervation patterns throughout hypothalamic, midbrain, and hindbrain components of the midshipman vocal motor pathway would show intrasexual differences between male midshipman reproductive morphs. Since our measurements included only TH-ir somata and fibers and not specific CA receptor subtypes (which are known to generate diverse effects on physiology) [e.g. Ericsson et al., 2013; Devries et al., 2015], we purposefully did not predict directional differences between morphs a priori. Our results provide evidence that intrasexual differences in the number of specific CA neurons and CA fiber innervation within the vocal motor system may provide neural substrates underlying alternative reproductive tactics in midshipman males within the summer reproductive season.

\section{Methods}

\section{Animals}

Nineteen plainfin midshipman fish (10 type I males and 9 type II males) were collected from intertidal nesting sites along Tomales Bay, Calif., USA, during the summer reproductive season. The animals were held in running seawater tanks at the University of California Bodega Marine Laboratory (BML) prior to sacrifice and tissue collection within $48 \mathrm{~h}$ of capture. Only type I males that had no eggs or fresh eggs in their nest were collected. This reflects males early in the reproductive season that are actively courting females at night. Once type I male nests are filled with developing embryos, they cease courtship and are fully parental, with a significant decline in circulating androgens [Knapp et al., 1999; Sisneros et al., 2004, 2009]. All protocols were in agreement with the guidelines set forth by the Institutional Animal Care and Use Committees of the City University of New York (CUNY) Brooklyn College and the University of California. Animals were anesthetized by immersion in seawater mixed with $0.025 \%$ benzocaine, weighed with a scale (Sartorius Mechatronics TE612; Göttingen, Germany), measured with a metric ruler, and perfused with ice-cold teleost Ringer's solution followed by ice-cold $4 \%$ paraformaldehyde in $0.1 \mathrm{M}$ phosphate buffer (PB). Testes were removed and weighed, and the gonadosomatic index (GSI) was calculated as the ratio of testes mass to body mass minus testes mass $\times 100$. Brains were removed, postfixed for $1 \mathrm{~h}$, and transferred to $0.1 \mathrm{M}$ phosphate buffer $(\mathrm{pH}$ 7.2). After incubation in $0.1 \mathrm{M} \mathrm{PB}$ with $30 \%$ sucrose for $48 \mathrm{~h}$, brains were sectioned on the coronal plane at $25 \mu \mathrm{m}$ with a cryostat and collected in 2 series onto positively charged slides. One series from each animal was used for this study and they were stored at $-80^{\circ} \mathrm{C}$ until processed for immunohistochemistry.

\section{Immunohistochemistry}

Immunohistochemistry was performed as follows: $20 \mathrm{~min}$ in $0.1 \mathrm{M}$ phosphate-buffered saline (PBS; $\mathrm{pH} 7.2$ ), $1 \mathrm{~h}$ in blocking solution (PBS $+10 \%$ donkey serum $+0.3 \%$ Triton $\mathrm{X}-100), 18 \mathrm{~h}$ at room temperature in anti-TH antibody raised in a mouse (Millipore, Temecula, Calif., USA) diluted 1:1,000 in the aforemen- tioned blocking solution, $5 \times 10$-min rinses in PBS $+0.5 \%$ donkey serum, and $2 \mathrm{~h}$ in anti-mouse secondary antibody conjugated to Alexa Flour 568 (Life Technologies, Carlsbad, Calif., USA) diluted 1:200 in the aforementioned blocking solution. Sections were extensively washed in PBS, after which a green fluorescent Nissl stain (NeuroTrace 500/525; Life Technologies) was diluted 1:200 in PBS, applied to the sections, and allowed to incubate for $20 \mathrm{~min}$ prior to being washed $4 \times$ for $10 \mathrm{~min}$ with PBS. Slides were coverslipped with Prolong Gold containing 4,6-diamidino-2-phenylindole nuclear stain (DAPI; Life Technologies), allowed to cure in the dark at room temperature for approximately $48 \mathrm{~h}$, and then sealed with nail polish and stored at $4^{\circ} \mathrm{C}$.

\section{Image Acquisition and Anatomy}

Images were acquired on an Olympus BX61 epifluorescence compound microscope using MetaMorph imaging and processing software (Molecular Devices, Sunnyvale, Calif., USA). Each nucleus was imaged with a $\times 20$ objective at a constant exposure time and light level. Each image was comprised of consecutively taken photomicrographs using Texas Red, GFP (where appropriate), and DAPI filter sets (Chroma, Bellow Falls, Vt., USA) within a $\mathrm{z}$-stack (sequential acquisition of a specified area with the focused position varied by a constant step ranging around a central plane) containing 5-9 levels, each with a step of $1 \mu \mathrm{m}$. These photomicrographs were then combined into a single projected image in MetaMorph using the Stack Arithmetic function, and nuclear boundaries were drawn after acquisition using DAPI to define the cytoarchitecture. The sampling strategy was determined per region to account for intrinsic variations in size between nuclei. In the case of tissue loss or damage, the opposite side of the brain was used (for unilateral sampling) or the section was omitted. The experimenter was blind to the treatment conditions of all of the slides analyzed.

\section{Cell Counts}

Numbers of TH-ir neurons were counted in the anterior parvocellular preoptic nucleus ( $\mathrm{PPa})$, the TPp, and the LC, which provide both local and widespread CA projections throughout the teleost brain. We also quantified $\mathrm{TH}$-ir neurons associated with vagal lobes (XL) and the area postrema (AP), which run parallel to and appear to provide significant CA input into the VMN [Forlano et al., 2014; Goebrecht et al., 2014]. Individual TH-ir neurons were counted only if the perimeter of the cell was clearly outlined with a labeled neurite in addition to having a nucleus that exhibited colocalization with DAPI. In each animal, the total number of TH-ir neurons was manually counted in each brain area of interest. In the event that the total cell number in a given nucleus shared a significant relationship with body size (see Statistics), the total number of TH-ir neurons for each subject was divided by its corresponding standard length (SL) to obtain a corrected measure of neurons per centimeter of body length. This method is in line with what has been done in previous studies examining brain cells in sexually polymorphic fish, and it has provided novel insight into the neural correlates of alternative reproductive tactics within males of the same species [Grober et al., 1994; Foran and Bass, 1998; Miranda et al., 2003].

Sampling of the $\mathrm{PPa}$ was done as previously described [Forlano et al., 2015], starting rostral to the horizontal commissure, with the appearance of parvocellular TH-ir cells clustered ventrolaterally to the midline in the caudal-most aspect of the nucleus, and continu- 
ing serially in the rostral direction until their disappearance, just rostral to the anterior commissure. A single image comprised of a Z-stack of 9 levels was taken unilaterally of $\mathrm{TH}$-ir neurons for an average of $10( \pm 2.5 \mathrm{SD})$ consecutive sections per animal. There was no difference in the number of sections between groups (unpaired $\mathrm{t}$ test, $\mathrm{p}>0.1$ ).

Sampling of the TPp was done as previously described [Petersen et al., 2013; Forlano et al., 2015] and began caudally with the appearance of dense clusters of large, pear-shaped TH-ir neurons lying medially to the medial forebrain bundle, extending ventrolaterally along the lateral edge of the paraventricular organ. Up to 3 images with a $\mathrm{z}$-stack of 9 levels were necessary to capture all THir neurons per section, and photomicrographs were aligned prior to analysis to avoid overlap. The TPp was analyzed serially for an average of $7.5( \pm 1.7 \mathrm{SD})$ sections in the caudal-to-rostral direction until the disappearance of large, pear-shaped TH-ir cells adjacent to the midline. The number of sections analyzed was not different between groups (unpaired t test, $\mathrm{p}>0.1$ ).

The LC was identified by the presence of TH-ir neurons dorsolateral to the medial longitudinal fasciculus in the isthmal region between the hindbrain and the midbrain. Sampling was done as previously described [Petersen et al., 2013; Forlano et al., 2015] and began with the bilateral appearance of $\mathrm{TH}$-ir neurons, continuing serially in the caudal-to-rostral direction for an average of $9.3( \pm 2.4$ SD) sections per animal until their disappearance. A single image with a $\mathrm{z}$-stack of 7 levels was taken of TH-ir neurons unilaterally per section. Type I males had more sections in this area of the brain (unpaired t test, $\mathrm{p}=0.0183$ ).

Sampling of the vagal-associated $\mathrm{TH}$-ir neurons started at the caudal-most extent of the VMN where large, extraventricular, fusiform bipolar TH-ir neurons first appear lateral to the dorsal half of the VMN throughout its extent. Sampling continued in the rostral direction into the XL where small, round, monopolar $\mathrm{TH}$-ir neurons are found near the ventricle [see Forlano et al., 2014, and Results]. In total, an average of 34.8 ( $\pm 10.8 \mathrm{SD})$ sections were sampled to encompass all vagal-associated $\mathrm{TH}$-ir neurons. With the exception of the rostral extent of the XL, where it was necessary to take 2 images to capture all visible TH-ir neurons, a single image of each section was taken unilaterally with a z-stack of 9 levels. Type I males had more sections throughout this area of the brain (unpaired t test, $\mathrm{p}=0.0032$ ).

The AP was located by the presence of $\mathrm{TH}$-ir neurons within a distinct cytoarchitectural boundary resembling a triangular wedge at the midline in the dorsal-most part of the section. Sampling began with the appearance of TH-ir neurons within the wedge and continued serially from the caudal-to-rostral direction for an average of 10.1 ( \pm 3.3 SD) sections per animal until their disappearance. A single image of each section was taken with a $\mathrm{z}$-stack of 9 levels. Type I males had more sections throughout this area of the brain (unpaired t test, $\mathrm{p}=0.0012$ ).

\section{Fiber Analysis}

$\mathrm{TH}$-ir fiber innervation was quantified by segmenting the THir signal of interest in each image using the Inclusive Threshold feature of MetaMorph. The threshold level for each image was set manually due to a subtle variation in background staining. Threshold levels were determined so that the pixels selected by MetaMorph were in conformance with what the blind observer deemed to be $\mathrm{TH}$-ir (e.g. distinct labeling above unlabeled structures in the same section). TH-ir fibers covering the area defined as the region of interest (ROI) were subsequently measured using the Region Statistics feature to obtain data on the total TH-ir area $\left(\mu \mathrm{m}^{2}\right)$, the total area sampled $\left(\mu \mathrm{m}^{2}\right)$, the average intensity (intensity independent of the area), and the integrated (total) intensity (TH-ir area divided by a $0.3225-\mu \mathrm{m}^{2}$ distance calibration constant and multiplied by the average intensity) per section in the hypothalamus and midbrain and per fractional area in the VMN. This approach has been similarly employed by other studies examining TH-ir fiber plasticity in songbirds and midshipman [LeBlanc et al., 2007; Matragrano et al., 2011; Forlano et al., 2015].

A measure of the percent thresholded area (total TH-ir area/ total area sampled) was used to compare the fiber innervation of the AT, vT, PAG, and PTT in order to control for potential confounders of body size on density measurements. The AT is located in the ventral hypothalamus, rostral to the dorsal periventricular hypothalamus and dorsal to the lateral hypothalamus. The AT was sampled as previously described [Petersen et al., 2013; Forlano et al., 2015]; an average of 5.8 ( \pm 1 SD) consecutive sections were imaged unilaterally on the left side of the brain using a $\mathrm{z}$ stack of 5 levels, and TH-ir fiber innervation was quantified within the field of view $\left(143,139 \mu \mathrm{m}^{2}\right)$. The vT was sampled unilaterally as previously described [Petersen et al., 2013] in serial sections on the left side of the brain starting at the level of the horizontal commissure. An ROI was drawn around the vT in the DAPI channel and transferred to the Texas Red channel where the TH-ir fiber density was quantified. On average, $3.6( \pm 1 \mathrm{SD})$ sections were used per animal. The number of sections analyzed throughout the AT and $\mathrm{vT}$ did not differ between groups (unpaired t test, $\mathrm{p}>0.5$ in both cases).

Sampling of the PAG and PTT started at the caudal division lying lateral to the granule layer of the valvula and dorsal to the nucleus lateralis valvulae [Goodson and Bass, 2002] and continued serially toward the rostral division of the nucleus. Images were taken every other section with a $\mathrm{z}$-stack of 5 levels for an average of $7.8( \pm 1.6 \mathrm{SD})$ sections per animal through the PAG and $5.8( \pm 1.5$ $\mathrm{SD})$ through the PTT. In some cases, both the PAG and the PTT could be captured in one image; however, it was necessary to take separate images of the PTT during the transition between the caudal and rostral divisions of the PAG. Two separate ROI were drawn in the DAPI channel and then transferred to the Texas Red channel where TH-ir fiber innervation was quantified. The PAG appears as a dense layer of cell bodies ventral to the cerebral aqueduct and medial to the periventricular cell layer of the torus semicircularis [Goodson and Bass, 2002; Kittelberger and Bass, 2013]. One ROI was drawn around the layer of cells comprising the PAG, lying ventral to the cerebral aqueduct. The other was drawn around the PTT, with the medial extent defined by the dorsomedial cell layer of the PAG, and the thin band of cells comprising the periventricular cell layer of the torus defined the lateral extent [Goodson and Bass, 2002; Kittelberger and Bass, 2013]. The number of sections analyzed throughout the PAG and PTT did not differ between groups (unpaired t test, $\mathrm{p}>0.2$ in both cases).

For the VMN, images were taken with a $\times 20$ objective every other section using a $\mathrm{z}$-stack of 5 levels for a total of 8 sections per animal spanning toward the rostral extent of the nucleus, with sampling ending at the point where the VMN decreased in size and did not take up the entire field of view. To account for the intrasexual dimorphism in the size of the VMN [Bass and Marchaterre, 1989; Bass et al., 1996], a design-based stereological approach was taken by overlaying a $5 \times 5$ rectangular grid on each 
Table 1. Summary of the statistics for morphometric data

\begin{tabular}{lcl}
\hline Morphotype & Type I males $(\mathrm{n}=10)$ & Type II males $(\mathrm{n}=9)$ \\
\hline SL, cm & $14.4-19.9^{\mathrm{a}}(16.7 \pm 1.8)$ & $7.7-11(9.5 \pm 1.2)$ \\
Body mass, g & $39.2-101.4^{\mathrm{a}}(62.7 \pm 21.3)$ & $5.3-16.3(11.1 \pm 4.2)$ \\
Gonad weight, g & $0.3-1.6(0.9 \pm 0.4)$ & $0.3-1.8(1 \pm 0.6)$ \\
GSI (\%) & $0.7-2.4(1.5 \pm 0.5)$ & $4.1-19.51^{\mathrm{a}}(10 \pm 5.3)$ \\
\hline
\end{tabular}

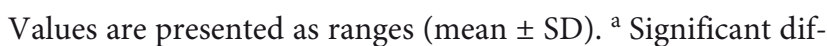
ference between morphs $(\mathrm{p}<0.05)$.

image and subsampling a constant fractional area $(86.11 \times 66.11$ $\mu \mathrm{m}$ or $5,692.7 \mu \mathrm{m}^{2}$ ) in a random systematic manner 5 times within the bounds of the nucleus in each section for a total of 40 fractional measurements per animal. In addition to the density of THir fibers per unit area, the area of overlap between $\mathrm{TH}$-ir fibers and fluorescent Nissl-stained motor neurons within the VMN was quantified using the Measure Colocalization function of MetaMorph.

In order to quantify the number of putative TH-ir contacts on individual motor neurons within the VMN, images were taken using a $\times 60$ oil-immersion objective from 2 of the aforementioned fractional samples per section. For this level of analysis, z-stacks were defined by setting an upper and lower limit based on the approximate upper and lower boundaries of each motor neuron and were sampled in $1-\mu \mathrm{m}$ steps. Fifteen individual motor neurons were sampled per animal using a random systematic method. A region was manually traced around each projected image of a motor neuron and subsequently dilated using a circular morphology filter with a constant diameter of $2.5 \mu \mathrm{m}$ to estimate putative $\mathrm{TH}$-ir contacts or CA release sites in very close proximity to the motor neuron soma. This was done because CA neuromodulatory signaling is not only confined to the synapse and often occurs extrasynaptically in a paracrine manner [McLean and Fetcho, 2004b; Descarries et al., 2008]. Each region was then overlaid onto the corresponding Texas Red image, and TH-ir fibers making putative contacts within the morphologically defined boundaries were segmented using the Integrated Morphometric Analysis feature of MetaMorph to obtain a measure of the number of putative $\mathrm{TH}$-ir contacts per motor neuron.

\section{Statistics}

Statistical analyses were performed using GraphPad Prism version 6 (La Jolla, Calif., USA). Pearson correlations were used to examine the relationship between total $\mathrm{TH}$-ir cell number and SL in each nucleus of interest in order to assess the need to control for differences in body size. A series of unpaired Student $t$ tests were utilized at the $\alpha=0.05$ significance level to compare TH-ir neuronal and fiber density data in each brain area of interest. A Welchcorrected $t$ test was used if the result of an $F$ test showed heterogeneity of variance between groups. A Mann-Whitney U test was used to compare body mass and GSI between morphs as the data did not meet Gaussian assumptions. As a way of determining the level of confidence in estimates of the total TH-ir cell number, an animal was excluded from the analysis if it was missing more than half the average number of sections sampled per animal for a given

Intrasexually Dimorphic Brain

Catecholamines in a Vocal Fish brain area. In general, individual animals missing more than half the average number of sections in an ROI possessed far fewer neurons relative to the rest of the data set. Statistics are reported as means \pm standard error (SE) unless otherwise noted.

\section{Results}

\section{Morphometrics}

Male morphs were easily distinguishable based on behavioral observations in the field, body size data, and gonad morphology as previously reported [Bass and Baker, 1990; Bass, 1992; Brantley and Bass, 1994; Bass et al., 1996]. As expected, type I males were significantly larger in SL $\left(\mathrm{t}_{17}=10.06, \mathrm{p}<0.0001\right)$ and body mass $(\mathrm{U}=0, \mathrm{p}<$ 0.0001 ), while type II males had a significantly greater GSI $(\mathrm{U}=0, \mathrm{p}<0.0001)$ (table 1). Type I males had significantly more sections throughout the LC, vagal nuclei, and AP (see Methods); however, there were no differences in the average number of $\mathrm{TH}$-ir cells per section between morphs and significant differences became apparent after adjusting the total cell number for body size (table 2). While this approach to controlling for differences in body size between treatment groups is not ideal (ANCOVA is the most appropriate), our data failed to meet the first assumption of that analysis (independence of the covariate and treatment effect) due to the dramatic difference in body size between morphs (table 1). As such, we utilized Pearson correlations to determine whether or not the total TH-ir cell number in each brain area of interest varied significantly with body size. It is important to note that the ratio (total $\mathrm{TH}$-ir neurons divided by SL) will only account for differences in body size if the relationship between the numerator and the denominator is significantly linear [Curran-Everett, 2013]. If this condition is not met, the computed ratio will misrepresent the true relationship between the total TH-ir cell number and SL, biasing normalized values toward the much smaller type II males. Therefore, we only reported normalized TH-ir cell data in nuclei where the total TH-ir cell number was significantly correlated to SL.

\section{TH-ir Cell Counts}

\section{Forebrain}

There were no significant differences in total $\mathrm{TH}$-ir cell number between morphs in the $\mathrm{PPa}$ (fig. 1b) and TPp (fig. 1d) (unpaired t test, $\mathrm{p}>0.1$ in both cases), and there was also no relationship between SL and the total number of PPa neurons ( $\mathrm{p}>0.1)$ or TPp neurons ( $\mathrm{p}>$ 0.07). 


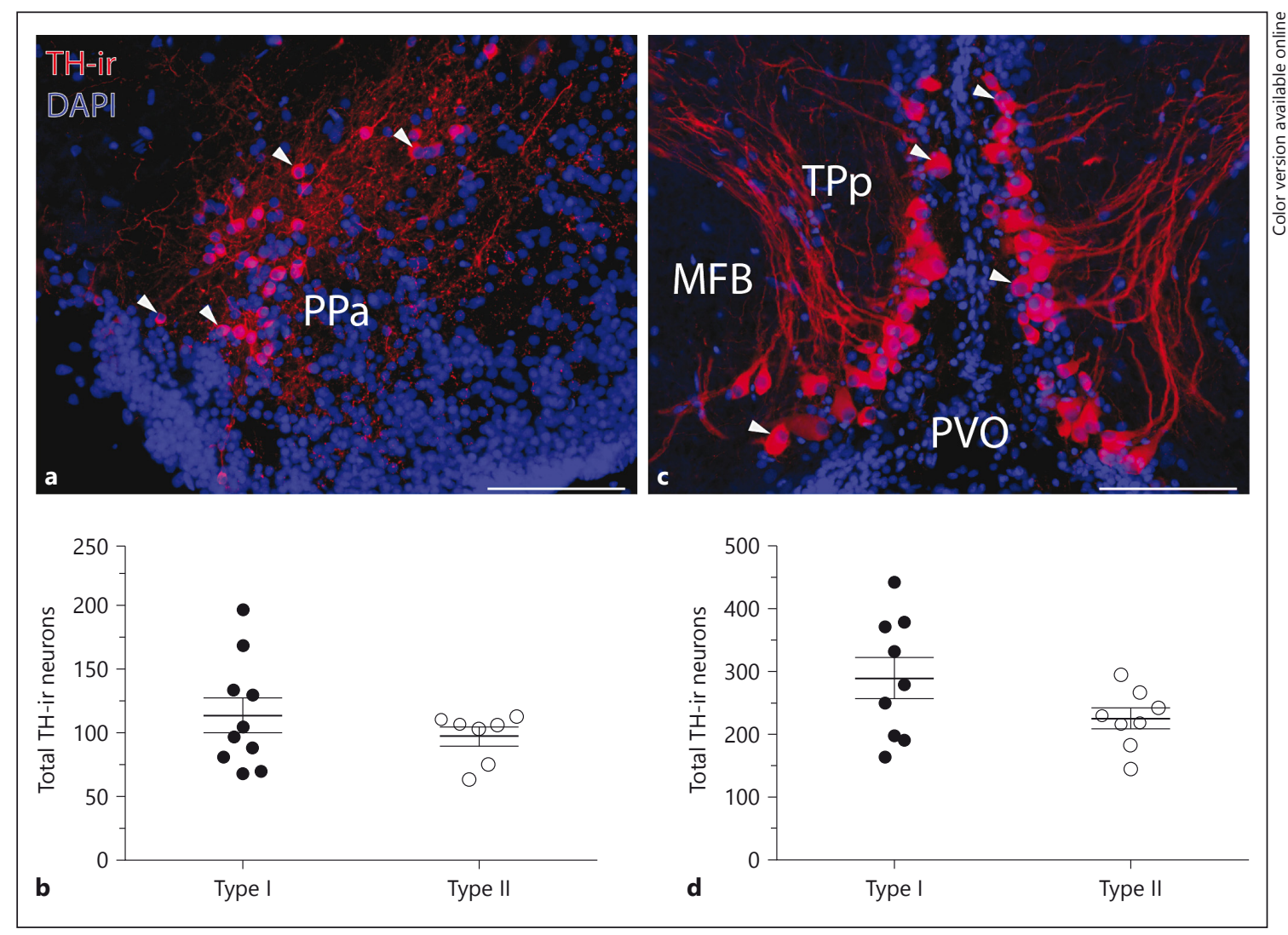

Fig. 1. Intrasexual morphometric comparison of forebrain $\mathrm{TH}$-ir nuclei. Micrographs depict TH-ir neurons (arrowheads) in representative transverse sections through the $\mathrm{PPa}(\mathbf{a})$ and $\mathrm{TPp}(\mathbf{c})$ in a type I male. The right edge of $\mathbf{a}$ is at the midline, and $\mathbf{c}$ is centered on the midline. $\mathrm{MFB}=$ Medial forebrain bundle; $\mathrm{PVO}=$ paraventricular organ. Scatter dot plots in $\mathbf{b}$ and $\mathbf{d}$ represent the mean $( \pm$ SE) number of total TH-ir neurons. Scale bars $=100 \mu \mathrm{m}$.

Table 2. Summary statistics for TH-ir cell count data

\begin{tabular}{|c|c|c|c|c|c|}
\hline ROI & Morphotype & Total cells & Sections & Cells/section & Cells/SL \\
\hline \multirow[t]{2}{*}{$\mathrm{PPa}$} & $\mathrm{TI}(\mathrm{n}=9)$ & $115.2 \pm 45.5$ & $10.8 \pm 2.6$ & $11.2 \pm 4$ & a \\
\hline & TII $(\mathrm{n}=7)$ & $98 \pm 19.7$ & $8.9 \pm 2$ & $11.5 \pm 3.3$ & a \\
\hline \multirow[t]{2}{*}{$\mathrm{TPp}$} & $\mathrm{TI}(\mathrm{n}=9)$ & $289.3 \pm 97.2$ & $8.1 \pm 1.8$ & $36.1 \pm 10.4$ & a \\
\hline & TII $(\mathrm{n}=8)$ & $225.1 \pm 46.7$ & $6.9 \pm 1.4$ & $34.3 \pm 12.3$ & a \\
\hline \multirow[t]{2}{*}{$\mathrm{LC}$} & TI $(\mathrm{n}=9)$ & $44.2 \pm 5.6$ & $10.6 \pm 2.3^{b}$ & $4.3 \pm 0.9$ & a \\
\hline & TII $(\mathrm{n}=8)$ & $37.6 \pm 8.9$ & $7.9 \pm 1.8$ & $5.0 \pm 1.3$ & a \\
\hline \multirow{2}{*}{ Vagal $_{\text {para }}$} & $\mathrm{TI}(\mathrm{n}=9)$ & $11 \pm 6.2$ & $7.3 \pm 4$ & $1.5 \pm 0.3$ & a \\
\hline & TII $(\mathrm{n}=9)$ & $12.1 \pm 5.2$ & $7 \pm 1.9$ & $1.7 \pm 0.4$ & a \\
\hline \multirow[t]{2}{*}{ Vagal $_{\text {extra }}$} & $\mathrm{TI}(\mathrm{n}=9)$ & $133.4 \pm 29.8$ & $41.7 \pm 9.7^{b}$ & $3.3 \pm 0.5$ & $7.9 \pm 1.9$ \\
\hline & TII $(\mathrm{n}=9)$ & $101.3 \pm 34.9$ & $27.9 \pm 6.9$ & $3.6 \pm 0.6$ & $10.6 \pm 3.1^{b}$ \\
\hline \multirow[t]{2}{*}{ Vagal $_{\text {all }}$} & TI $(\mathrm{n}=9)$ & $145.6 \pm 34.9$ & $41.7 \pm 9.7^{b}$ & $3.5 \pm 0.5$ & $8.7 \pm 2.1$ \\
\hline & TII $(\mathrm{n}=9)$ & $112 \pm 37.7$ & $27.9 \pm 6.9$ & $4 \pm 0.7$ & $11.9 \pm 3.3^{b}$ \\
\hline \multirow[t]{2}{*}{$\mathrm{AP}$} & $\mathrm{TI}(\mathrm{n}=9)$ & $121.7 \pm 29.4^{\mathrm{b}}$ & $12.3 \pm 2.7^{\mathrm{b}}$ & $10.1 \pm 2.7$ & $7.2 \pm 1.4$ \\
\hline & TII $(\mathrm{n}=9)$ & $78.4 \pm 35.3$ & $7.9 \pm 2.1$ & $10.0 \pm 3.7$ & $8.4 \pm 3.5$ \\
\hline
\end{tabular}

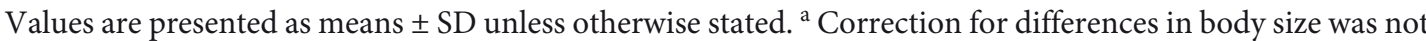
justified due to an insignificant relationship between total cell number and SL. ${ }^{\mathrm{b}}$ Significant difference between morphs $(\mathrm{p}<0.05)$. 


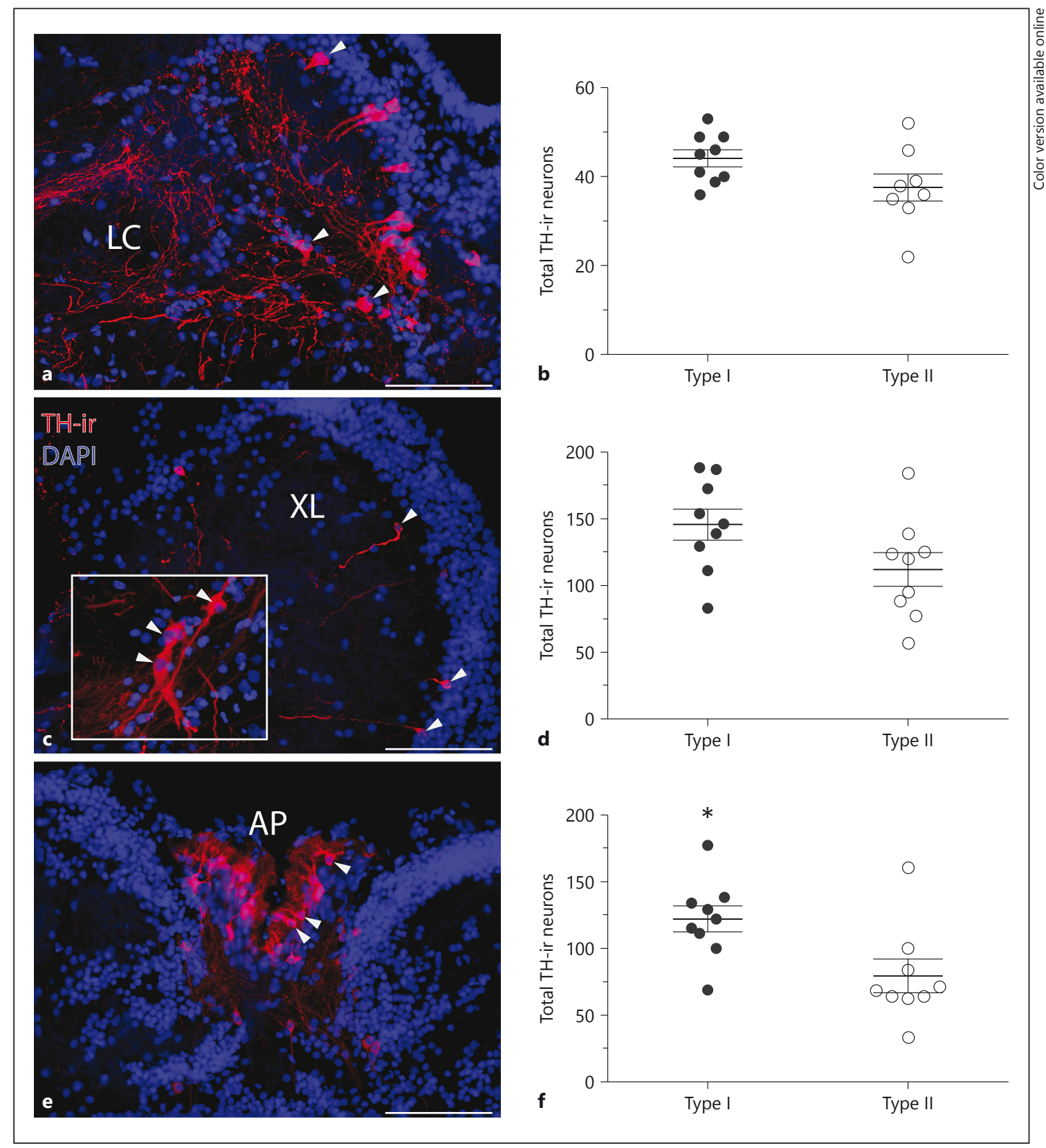

Fig. 2. Intrasexual morphometric comparison of hindbrain TH-ir nuclei. Micrographs depict TH-ir neurons (arrowheads) in representative transverse sections through the LC (a), the XL (c), and the AP (e) in a type II male. The right edges of $\mathbf{a}$ and $\mathbf{c}$ are at the midline of the brain, and $\mathbf{e}$ is centered on the midline. The inset

\section{Hindbrain}

Similar to forebrain nuclei, there was not a significant difference in total cell number between morphs in the LC (unpaired t test, $\mathrm{p}>0.08$ ) (fig. $2 \mathrm{~b}$ ), and there was no relationship between SL and the total number of LC TH-ir neurons $(\mathrm{p}>0.1)$. With regard to the total $\mathrm{TH}$-ir cell in c depicts larger extraventricular vagal neurons lying caudal and ventrolateral to smaller paraventricular neurons in the XL. Scatter dot plots in $\mathbf{b}, \mathbf{d}$, and $\mathbf{f}$ represent the mean $( \pm \mathrm{SE})$ number of total TH-ir neurons. ${ }^{*} \mathrm{p}=0.0123$. Scale bars $=100 \mu \mathrm{m}$.

number in the vagal nuclei, there was no difference between morphs (unpaired t test, $\mathrm{p}>0.07$ ) (fig. 2d), but type I males did have significantly more total neurons in the $\mathrm{AP}\left(\mathrm{t}_{16}=2.819, \mathrm{p}=0.0123\right.$; type $\mathrm{I}=121.7 \pm 9.815$ and type $\mathrm{II}=78.44 \pm 11.78)$ (fig. 2f). However, there were significant relationships between SL and the total numbers of 


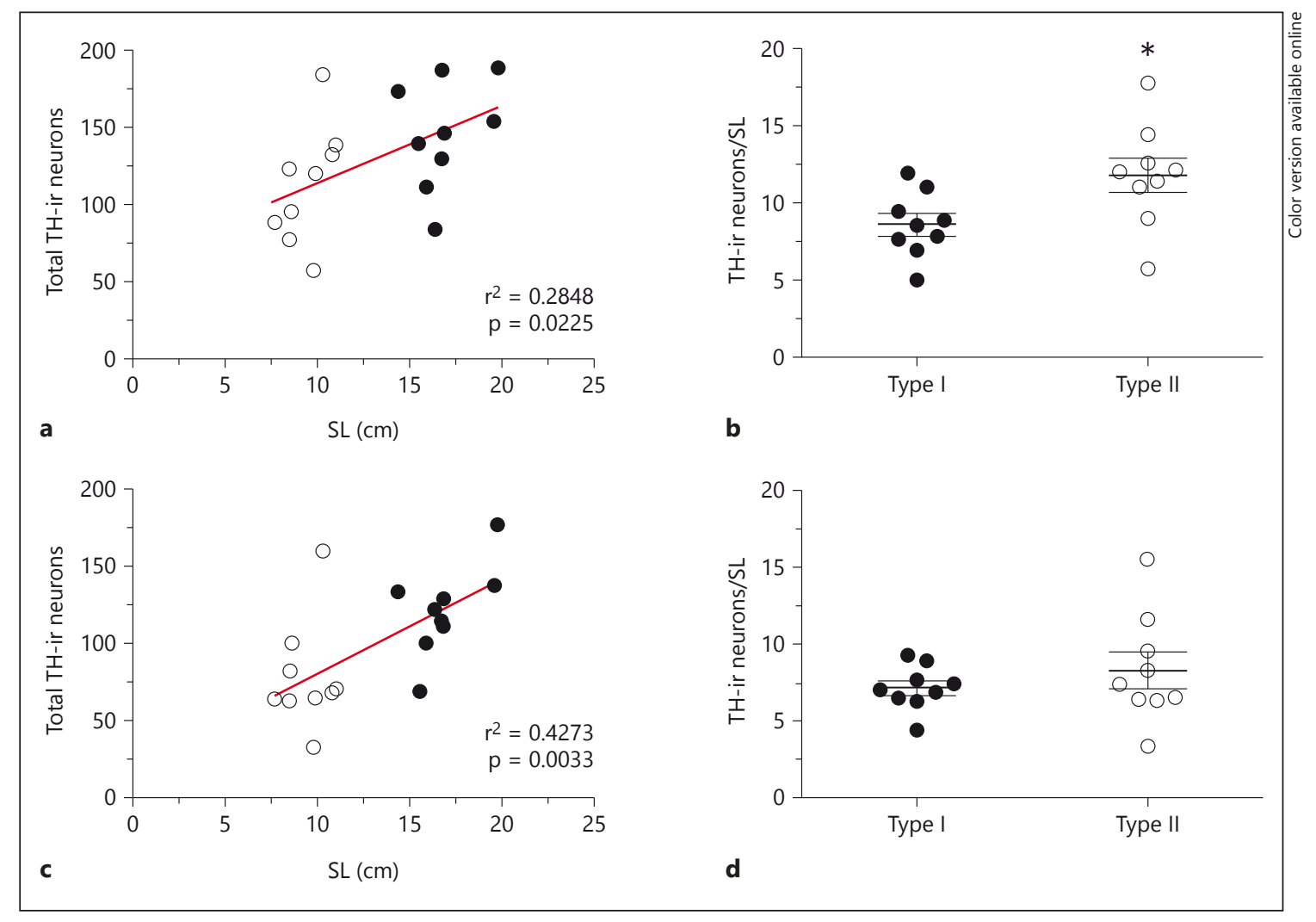

Fig. 3. Intrasexual morphometric analysis of the relationship between total TH-ir cell number and body size in the hindbrain. Pearson correlations of total TH-ir cell number scaled to SL in the vagal-associated nuclei (paraventricular and extraventricular cells combined) (a) and the AP (c). Closed circles represent type I

TH-ir neurons associated with vagal nuclei $\left(\mathrm{r}^{2}=0.2867\right.$, $\mathrm{p}=0.022)$ (fig. 3a) and AP $\left(\mathrm{r}^{2}=0.4273, \mathrm{p}=0.0033\right)$ (fig. 3c). After correcting for differences in body size, type II males had $31.4 \%$ more vagal $\mathrm{TH}$-ir neurons per centimeter of body length $\left(\mathrm{t}_{16}=2.538, \mathrm{p}=0.0219\right.$; type $\mathrm{I}=$ $8.637 \pm 0.7007$ and type II $=11.85 \pm 1.1056$ ) (fig. $3 b$ ). There was no difference between morphs after correcting for body size in the AP (Welch-corrected t test, $\mathrm{p}>0.3$ ) (fig. 3d).

Relative Contribution of Paraventricular and

Extraventricular TH-ir Neurons to the Variation in

Normalized Vagal-Associated Cell Density

Our initial analysis of CA vagal neurons included all cells counted throughout this area of the brain. In zebra fish, TH-ir vagal cells are demarcated into small, monopolar, paraventricular dopaminergic and larger, bipolar, extraventricular noradrenergic subgroups using an antibody raised against DA $\beta$-hydroxylase (DBH-ir) [Kaslin males, and open circles represent type II males. Scatter dot plots in b and $\mathbf{d}$ represent the mean $( \pm \mathrm{SE})$ number of TH-ir neurons corrected for body size. ${ }^{*} \mathrm{p}=0.0219$. See table 2 for the statistical breakdown of the TH-ir vagal subgroups. and Panula, 2001]. Since the total number of vagal TH-ir neurons varied with body size in our study (fig. 3a), and type II males had more neurons per centimeter of body length (fig. 3b), we wanted to determine which neuroanatomical subgroup contributed to the variation in normalized cell number between morphs. There was no difference in the total number of paraventricular TH-ir cells between morphs ( $p>0.6)$, but there was a trend for type I males having more total extraventricular cells $\left(\mathrm{t}_{16}=\right.$ $2.102, \mathrm{p}=0.0518$; type $\mathrm{I}=133.4 \pm 9.916$ and type $\mathrm{II}=$ $101.3 \pm 11.62)$. While the total number of paraventricular cells was not correlated to body size $(p>0.8)$, there was a significant relationship between the total number of extraventricular vagal cells and SL $\left(\mathrm{r}^{2}=0.3241, \mathrm{p}=0.0137\right)$. After size correction, type II males had $28.5 \%$ more extraventricular vagal $\mathrm{TH}$-ir neurons per centimeter of body length $\left(\mathrm{t}_{16}=2.204, \mathrm{p}=0.0425\right.$; type $\mathrm{I}=7.992 \pm 0.63$ and type II $=10.65 \pm 1.029)$. It is important to note that out of all of the $\mathrm{TH}$-ir vagal cells measured, extraventricular 

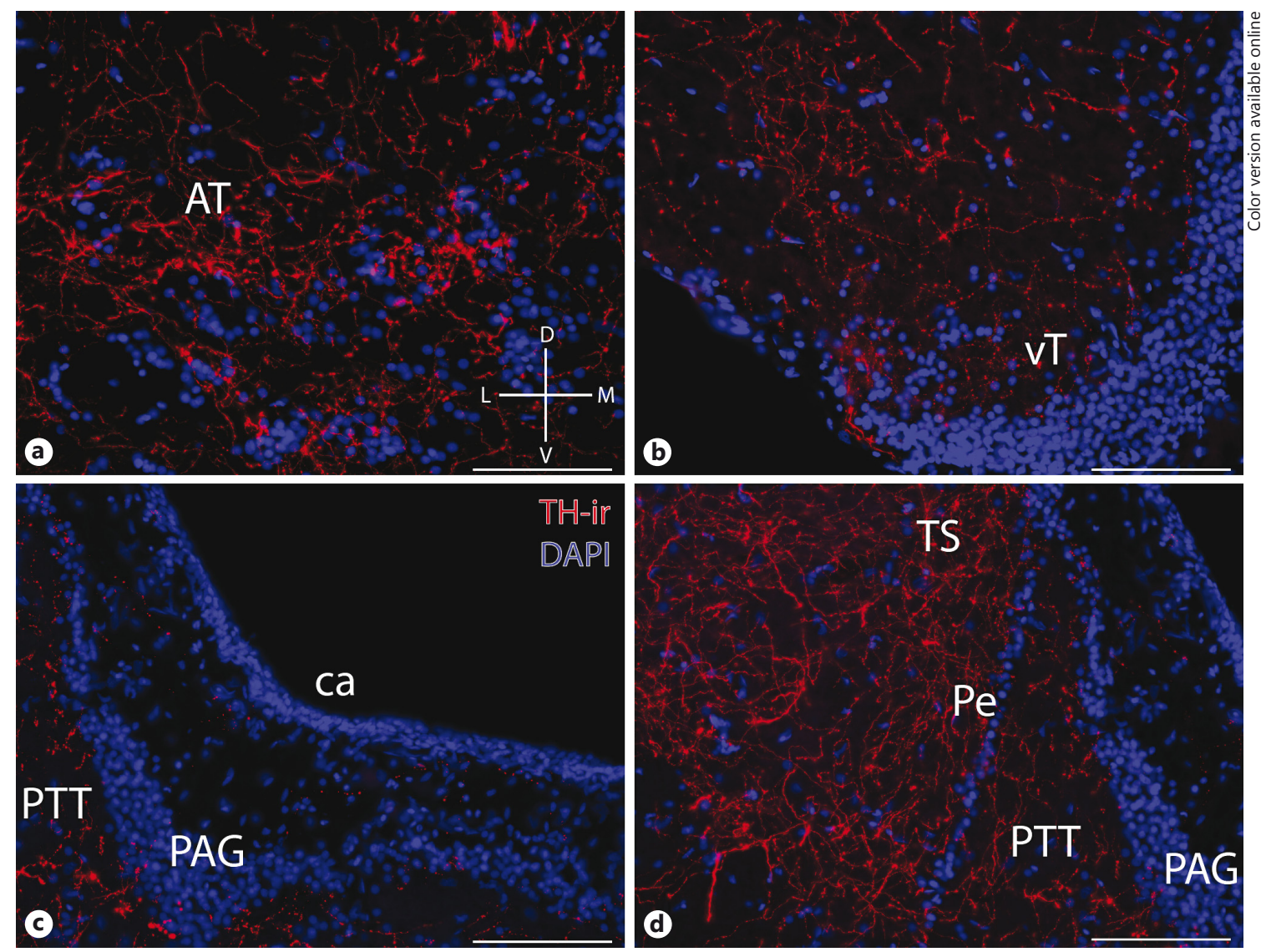

Fig. 4. Micrographs showing representative transverse sections through the hypothalamic and midbrain components of the vocal motor pathway in a type II male. Anterior tuberal hypothalamus (AT) (a), vT (b), midbrain PAG (c), and PTT (d). The compass in the bottom right corner of $\mathbf{a}$ indicates the anatomical orientation across all images as follows: $\mathrm{D}=$ dorsal, $\mathrm{V}=$ ventral, $\mathrm{M}=$ medial, and $\mathrm{L}=$ lateral. $\mathrm{ca}=$ Cerebral aqueduct $; \mathrm{Pe}=$ periventricular cell layer of the torus semicircularis; TS = torus semicircularis. The mean $( \pm$ SE) TH-ir fiber density for type I versus type II males was: AT, $7.37 \pm 1.28$ vs. $9.1 \pm 1.19 \%$; vT, $2.59 \pm 0.12$ vs. $3.1 \pm 0.25 \%$; PAG, $1.9 \pm 0.28$ vs. $1.84 \pm 0.31 \%$, and PTT, $7.51 \pm 0.82$ vs. $7.96 \pm$ $0.89 \%$. Scale bars $=100 \mu \mathrm{m}$. cells comprised over $90 \%$ of those subsampled (table 2 ). These results demonstrate that putatively noradrenergic extraventricular vagal $\mathrm{TH}$-ir cells contribute to the variation in neuron number corrected for body size between morphs.

\section{TH-ir Fiber Analysis}

Hypothalamus, Midbrain, and Hindbrain

There were no significant differences in the percent area covered by $\mathrm{TH}$-ir fibers or intensity within the AT, $\mathrm{vT}, \mathrm{PAG}$, or PTT (unpaired t test, $\mathrm{p}>0.07$ in all cases) (fig. 4). Within the VMN, type II males had a greater THir fiber density per fractional area $\left(5,692.7 \mu \mathrm{m}^{2}\right)\left(\mathrm{t}_{16}=\right.$ $6.801, \mathrm{p}<0.0001$; type $\mathrm{I}=91.63 \pm 10.04 \mu \mathrm{m}^{2}$ and type $\mathrm{II}=$ $246.8 \pm 20.48 \mu \mathrm{m}^{2}$ ) (fig. 5e). While significant differences in integrated (total) intensity [measured in arbitrary units
(AU) ] reflected differences in fiber density $\left(\mathrm{t}_{16}=6.496\right.$, $\mathrm{p}<0.0001$; type $\mathrm{I}=96,842 \pm 10,761 \mathrm{AU}$ and type $\mathrm{II}=$ $246,657 \pm 20,397 \mathrm{AU}), \mathrm{TH}$-ir fibers in the VMN of type I males had a higher average intensity per fractional area $\left(\mathrm{t}_{16}=3.349, \mathrm{p}=0.0041\right.$; type $\mathrm{I}=112.1 \pm 1.213 \mathrm{AU}$ and type $\mathrm{II}=107.1 \pm 0.8978 \mathrm{AU})$. As expected, a greater portion of the sampling area was taken up by motor neuron somata in type I males [Bass and Marchaterre, 1989; Bass et al., 1996] $\left(t_{16}=3.75, p=0.0017\right.$; type $\mathrm{I}=1,053 \pm 54.38 \mu \mathrm{m}^{2}$ and type II $=774.1 \pm 50.74 \mu \mathrm{m}^{2}$ ). The area of overlap between $\mathrm{TH}$-ir fibers and motor neuron somata was greater in type II males $\left(\mathrm{t}_{16}=6.79, \mathrm{p}<0.0001\right.$; type $\mathrm{I}=9.036 \pm$ $2.067 \mu \mathrm{m}^{2}$ and type II $=25.06 \pm 1.14 \mu \mathrm{m}^{2}$ ). Additionally, type II males had $44.1 \%$ more putative $\mathrm{TH}$-ir contacts per motor neuron (Welch-corrected $t_{7.56}=3.793, \mathrm{p}=0.0059$; type $\mathrm{I}=7.666 \pm 0.3985$ and type $\mathrm{II}=12 \pm 1.071$ ) (fig. 5 f). 
Fig. 5. Intrasexual morphometric comparison of TH-ir fiber density within the VMN. Micrographs depict representative transverse sections through the VMN at low and high magnifications in a type $I(\mathbf{a}, \mathbf{c})$ and type II (b, d) male. a-d Arrowheads in c and $\mathbf{d}$ indicate punctate-type contacts on individual motor neurons. Scatter dot plots represent the mean $( \pm \mathrm{SE}) \mathrm{TH}$-ir fiber density per fractional area $\left(\mathbf{e} ; 5,692.7 \mu \mathrm{m}^{2}\right)$ and the mean $( \pm \mathrm{SE})$ number of putative TH-ir contacts per cell (f). ${ }^{* * * *} \mathrm{p}<0.0001 ;{ }^{* *} \mathrm{p}=$ 0.0059 . Scale bars $=100 \mu \mathrm{m}(\mathbf{a}, \mathbf{b})$ and 35 $\mu \mathrm{m}(\mathbf{c}, \mathbf{d})$.
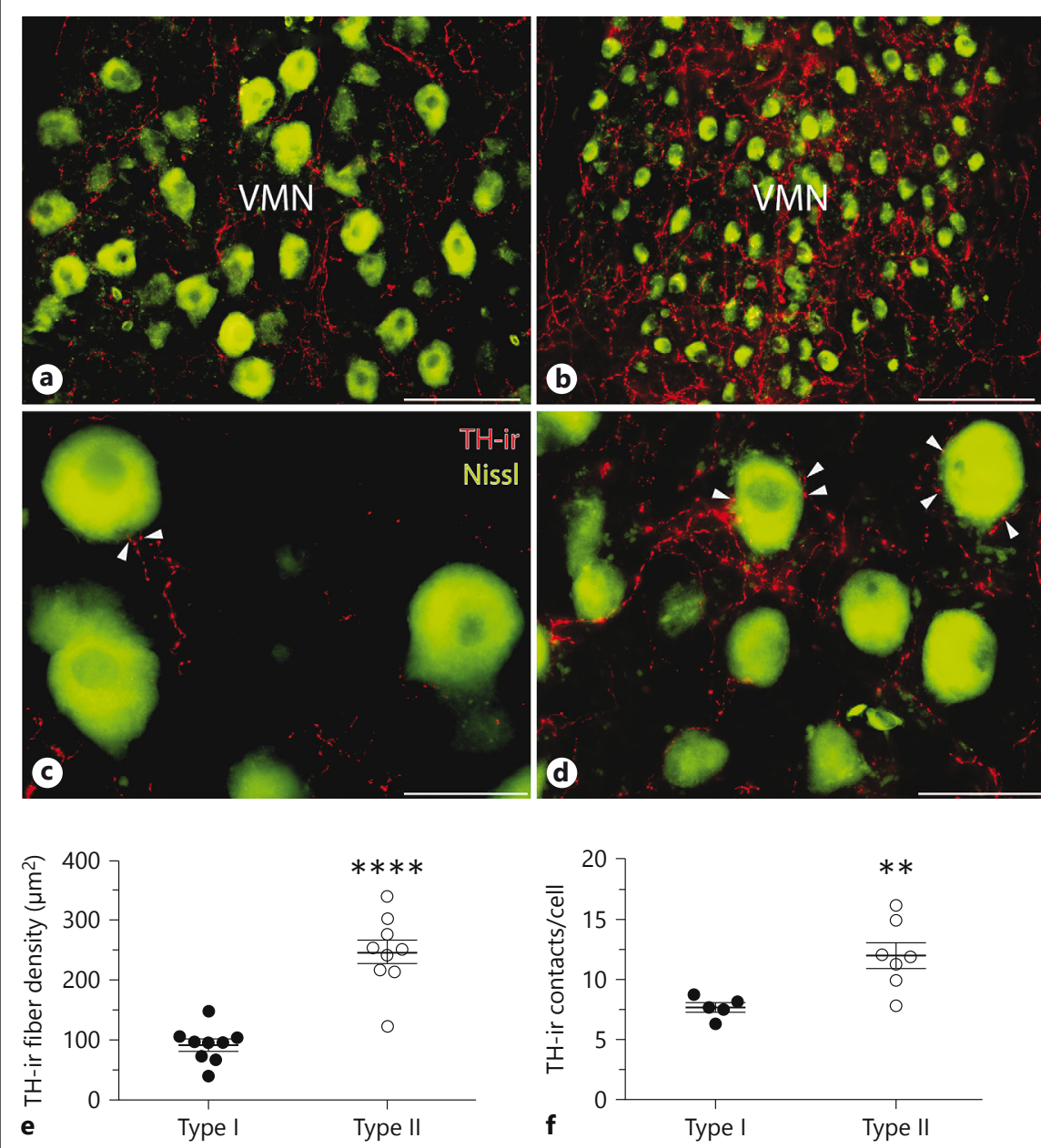

\section{Discussion}

Our study found intrasexual dimorphisms in TH-ir neurons and fiber density in close proximity to and within a major component of the hindbrain VPG, providing compelling evidence that differences in brain catecholamines are an underlying characteristic within the suite of traits that are divergent in male midshipman exhibiting alternative reproductive tactics [see Bass and Forlano, 2008]. Interestingly, quantitative analyses of $\mathrm{TH}$-ir fiber innervation in vocal nuclei in the forebrain, midbrain, and hindbrain only revealed a significant difference between male morphs in the VMN that spans the hindbrain-spinal transition [Bass et al., 2008]. This difference was evident as both a greater overall density of TH-ir fibers per fractional area of the nucleus and a greater number of putative contacts per VMN soma in type II males. Our measure of contacts per motor neuron included pu- tative CA release sites in close proximity to the edges of sampled motor neurons due to the fact that it is well established that catecholamines are released volumetrically at nonclassical synapses in a paracrine fashion [Descarries et al., 2008]. Although inter- and intrasexual dimorphisms of VMN neurons and their efferent muscle targets have been well characterized physiologically and morphologically [Bass and Marchaterre, 1989; Bass and Baker, 1990; Bass et al., 1996], this is the first report of morph differences in efferent fibers to the VMN. It is possible that without TH-ir labeling, morph differences in VMN inputs may not be obvious, especially if $\mathrm{TH}$-ir neurons do not form classical synapses in this area. This could explain why an earlier TEM study did not detect differences in the synaptology of the VMN between morphs [Bass and Marchaterre, 1989]. It is interesting to note that we found a small $(\sim 5 \%)$ but significant difference in the average intensity of $\mathrm{TH}$-ir fibers in the VMN that was greater in 
type I males, although the biological relevance of such a small difference is questionable. Average fiber intensity measurements may reflect differences in enzyme expression independent of the density of TH-ir efferent inputs and may indicate a tradeoff of CA production per axon versus greater numbers of efferents per target area.

\section{Origin of Male Morph Differences in TH-ir Fiber Innervation of the VMN}

Although the VMN appears to receive input from neighboring TH-ir neurons in the XL and the AP [Forlano et al., 2014], descending projections from the TPp and $\mathrm{LC}$ could also contribute to $\mathrm{TH}$-ir fibers terminating in the VMN, consistent with the known descending projection patterns of these nuclei into the hindbrain and spinal cord of teleosts (notably the TPp and its diencephalospinal projections as proposed homologs to dopaminergic A11 neurons in mammals) [McLean and Fetcho, 2004a, b; Tay et al., 2011; Schweitzer et al., 2012; Forlano et al., 2014; Jay et al., 2015]. Since we utilized TH-ir as a marker for CA neurons, we were unable to distinguish between the relative contributions of dopaminergic and noradrenergic fibers in the VMN. However, after differentiating between paraventricular and extraventricular vagal TH-ir neurons [Ma, 1997; Kaslin and Panula, 2001], we determined that the putatively noradrenergic extraventricular neurons contributed to the variation in normalized TH-ir cell density between morphs. This suggests a possible differential noradrenergic modulation of vocal motor function between type I and type II males, as they appear to provide significant CA input into the $\mathrm{VMN}$ of midshipman [Forlano et al., 2014]. These vagal nuclei are also proposed homologs of the A2 group and its subset in rats, which indeed show a similar neuroanatomical distribution of TH- and DBH-containing neurons. [Hökfelt et al., 1984; Kaslin and Panula, 2001]. Future studies will need to further elucidate any morph differences in CA type, but perhaps more importantly they will need to identify the expression of various CA receptor subtypes which would give insight into variations of modulatory input and action on VMN neurons (see below). Although we did not find differences in TH-ir fiber innervation in higher-order vocal centers, it is also possible that a differential input of DA versus NA may underlie the same total CA fiber density between morphs.

CA innervation and multiple types of DA and NA receptors have been localized not only on spinal motor neurons across vertebrate taxa [Svensson et al., 2003; McLean and Fetcho, 2004b; Tay et al., 2011; Zhao et al., 2015] but also more importantly on homologous VPG nuclei across

Intrasexually Dimorphic Brain

Catecholamines in a Vocal Fish vertebrates. For instance, a recent study in rats revealed that expiratory laryngeal motor neurons in the nucleus ambiguus receive close appositions from descending $\mathrm{TH}$ ir varicosities that originate, in part, from the AP and nucleus tractus solitarius [Zhao et al., 2015]. These caudal $\mathrm{TH}$ - ir groups also likely provide local innervation of the nucleus ambiguus in mammals [Rinaman, 2011], the tracheosyringeal division of the hypoglossal motor nucleus in birds [Bottjer, 1993; Mello et al., 1998; Appeltants et al., 2001], and the vagal motor nucleus and inferior reticular formation in amphibians [Gonzalez and Smeets, 1991], all comparable vocal areas to midshipman VPG nuclei [Bass et al., 2008; Bass, 2014]. As a result, CA modulation of vocal motor patterning may also be a conserved vertebrate character [Forlano et al., 2014].

\section{Functional Implications of Morph Differences in}

TH-ir Innervation of the VMN

Although electrical stimulation at various levels along the vocal motor pathway can elicit short, isolated fictive agonistic 'grunts' in type II males and females [Goodson and Bass, 2000; Remage-Healey and Bass, 2007], these are rarely if ever heard in field recordings [Brantley and Bass, 1994]. Type II males are referred to as 'sneaker' males which attempt to steal fertilizations from type I males by surreptitiously gaining access to a type I nest when a female is in the process of depositing her eggs [Brantley and Bass, 1994]. Therefore, minimizing vocalizations would be advantageous for successfully employing this reproductive tactic. Our findings, which demonstrate a strong inverse relationship between the density of $\mathrm{TH}$-ir innervation in the VMN and the predominant vocal phenotype, suggest that catecholamines may function, in part, to directly inhibit vocal behavior during the breeding season.

There are multiple examples from diverse taxa that show an inhibitory action of NA and or DA on vocal circuitry and behavior, although this can vary depending on the receptor that is targeted. Preliminary experimental work in midshipman has found that both $\mathrm{D}_{1}$ - and $\mathrm{D}_{2}$-like receptors contribute to DA-induced suppression of fictive vocalizations initiated at the level of the PAG [Heisler and Kittelberger, 2012]. Likewise, the $d r d 2$ transcripts which encode $\mathrm{D}_{2}$-like DA receptor subtypes are upregulated in the VMN relative to the surrounding hindbrain [Feng et al., 2015]. In zebra finches, NA suppresses activity in the robust nucleus of the arcopallium, a forebrain premotor song control nucleus, via $\alpha_{2}$-adrenergic receptors [Solis and Perkel, 2006]. Similarly NA inhibits the medullary respiratory rhythm generator in newborn rats [Errchidi et al., 1991]. In contrast, NA can have excitato- 
ry effects on the firing properties of hypoglossal motor neurons in juvenile rats via $\alpha_{1}$-adrenoceptors [Parkis et al., 1995]. The inhibitory effect of DA is evident in lamprey, where DA can presynaptically inhibit glutamatergic reticulospinal transmission through $\mathrm{D}_{2}$ receptors [Svensson et al., 2003]. Interestingly, TPp neurons projecting to spinal motor neurons in larval zebrafish show different firing patterns during locomotion and while stationary, and this appears to be dependent on the synaptic input to these DA neurons [Jay et al., 2015]. In green tree frogs, activation of $\mathrm{D}_{2}$-like receptors has an inhibitory effect on male advertisement calling, while $\mathrm{D}_{1}$-like and nonspecific DA agonists have no effect on vocal behavior [Creighton et al., 2013]. In adult rats, $\mathrm{D}_{1^{-}}$and- $\mathrm{D}_{2}$-receptor antagonism resulted in fewer ultrasonic vocalizations, including a delayed initiation of calls and a subdued signal complexity [Ringel et al., 2013].

\section{Possible Mechanisms for Intrasexual Male Differences in $\mathrm{TH}$-ir}

Males were all collected early in the breeding season, characterized as a period of intense vocal courtship by type I males and corresponding sneaking behavior by type IIs [Brantley and Bass, 1994; Sisneros et al., 2004, 2009]; therefore, the present study provides a snapshot of brain CA density and distribution in this phase of the reproductive period. At this time of collection, type I males are known to have high levels of circulating 11-ketotestosterone compared to later in the summer during the parental phase [Knapp et al., 1999; Sisneros et al., 2004], while type II males have undetectable 11-ketotestosterone; they have higher plasma levels of testosterone and cortisol compared to type Is [Brantley et al., 1993; Arterbery et al., 2010a]. Male morphs are divergent not only in circulating steroid levels but also in brain aromatase, $11 \beta$-hydroxylase, and $11 \beta$-hydroxysteroid dehydrogenase, as well as glucocorticoid and estrogen receptor expression [Schlinger et al., 1999; Bass and Forlano, 2008; Arterbery et al., 2010a, b; Fergus and Bass, 2013]. Because steroid hormones are known to regulate CA expression and/or correlate with $\mathrm{TH}$-ir neuron number and fiber density [Wilczynski et al., 2003; Weltzien et al., 2006; LeBlanc et al., 2007; Matragrano et al., 2011], differential circulating or brain-derived steroid hormones may underlie morph differences in the number of $\mathrm{TH}$-ir vagal neurons and innervation patterns of $\mathrm{TH}$-ir fibers terminating into the VMN. Since steroid hormone levels vary seasonally and with vocal behavior in type I males [Sisneros et al., 2004; Genova et al., 2012], there may yet prove to be plasticity in $\mathrm{TH}$-ir innervation of the VMN within male morphs between seasons (and likely between the courtship and parental phases within the summer reproductive season in type I males), similar to our findings in the auditory system of females [Forlano et al., 2015]. Compellingly, the density of $\alpha_{2}$-adrenergic receptors in the song control nuclei of male European starlings varies seasonally, showing an inverse relationship between circulating testosterone, song nuclei volume, and singing behavior [Riters et al., 2002; Heimovics et al., 2011].

\section{Conclusions}

Differential numbers of $\mathrm{TH}$-ir vagal neurons proximal to the VMN and CA fiber innervation of the VMN between divergent male morphs of the same species support a role for catecholamines as important modulators of vocal behavior related to reproductive phenotype. Further studies will be necessary to reveal the distribution of specific CA subpopulations and their receptor subtypes in the vocal motor pathway of midshipman and how they may relate to differences in vocal behavior.

\section{Acknowledgements}

We thank the UC Davis BML, the Sisneros lab, and Midge Marchaterre for logistical support, Chris Petersen for assisting with perfusions and providing analytical insight, and Chris Braun and Thomas Preuss for imparting constructive feedback on an earlier version of this paper. We also wish to thank Frank Burbrink, Frank Grasso, Jonathan Perelmuter, and Sunny Scobell for valuable discussions on matters of biometry, and Spencer Kim for histological assistance and contributing authoritative macroinstruction in MetaMorph. Lastly, we thank two anonymous reviews that improved the quality of this paper.

This study was funded by National Institutes of Health grant No. SC2DA034996 (to P.M.F.) and CUNY Graduate Center Doctoral Student Research Grant No. 9 (to Z.N.G.).

References

\footnotetext{
Appeltants D, Ball GF, Balthazart J (2001): The distribution of tyrosine hydroxylase in the canary brain: demonstration of a specific and sexually dimorphic catecholaminergic innervation of the telencephalic song control nulcei. Cell Tissue Res 304:237-259.

Appeltants D, Ball GF, Balthazart J (2002a): The origin of catecholaminergic inputs to the song control nucleus RA in canaries. Neuroreport 13:649-653.

Appeltants D, Ball GF, Balthazart J (2002b): Noradrenergic control of auditory information processing in female canaries. Behav Brain Res 133:221-235.
} 
Arterbery AS, Deitcher DL, Bass AH (2010a): Corticosteroid receptor expression in a teleost fish that displays alternative male reproductive tactics. Gen Comp Endocrinol 165:83-90.

Arterbery AS, Deitcher DL, Bass AH (2010b): Divergent expression of $11 \beta$-hydroxysteroid dehydrogenase and $11 \beta$-hydroxylase genes between male morphs in the central nervous system, sonic muscle and testis of a vocal fish. Gen Comp Endocrinol 167:44-50.

Barth C, Villringer A, Sacher J (2015): Sex hormones affect neurotransmitters and shape the adult female brain during hormonal transition periods. Front Neurosci 9:1-20.

Bass AH (1992): Dimorphic male brains and alternate reproductive tactics in a vocalizing fish. Trends Neurosci 15:139-145.

Bass AH (1996): Shaping brain sexuality. Am Sci 84:352-363.

- Bass AH (2014): Central pattern generator for vocalization: is there a vertebrate morphotype? Curr Opin Neurobiol 28:94-100.

- Bass AH, Baker R (1990): Sexual dimorphisms in a vocal control system of a teleost fish: morphology of physiologically identified neurons. J Neurobiol 21:1155-1168.

- Bass AH, Forlano PM (2008): Neuroendocrine mechanisms of alternative reproductive tactics: the chemical language of reproductive and social plasticity; in Oliveira RF, Taborsky M, Brockmann HJ (eds): Alternative Reproductive Tactics: an Integrative Approach. Cambridge, Cambridge University Press, pp 109-131.

- Bass AH, Gilland EH, Baker R (2008): Evolutionary origins for social vocalization in a vertebrate hindbrain-spinal compartment. Science 321:417-421.

Bass AH, Horvath BJ, Brothers EB (1996): Nonsequential developmental trajectories lead to dimorphic vocal circuitry for males with alternative reproductive tactics. J Neurobiol 30: 493-504.

Bass AH, Marchaterre MA (1989): Sound-generating (sonic) motor system in a teleost fish (Porichthys notatus): sexual polymorphisms and general synaptology of sonic motor nucleus. J Comp Neurol 286:154-169.

Bass AH, Marchaterre MA, Baker R (1994): Vocal-acoustic pathways in a teleost fish. J Neurosci 14:4025-4039.

Bass AH, McKibben JR (2003): Neural mechanisms and behaviors for acoustic communication in teleost fish. Prog Neurobiol 69:1-26.

Bottjer SW (1993): The distribution of tyrosine hydroxylase immunoreactivity in the brains of male and female zebra finches. J Neurobiol 24:51-69.

- Brantley RK, Bass AH (1994): Alternative male spawning tactics and acoustic signaling in the plainfin midshipman fish, Porichthys notatus. Ethology 96:213-232.

Brantley RK, Wingfield JC, Bass AH (1993): Hormonal bases for male teleost dimorphisms: sex steroid levels in Porichthys notatus, a fish with alternative reproductive tactics. Horm Behav 27:332-347.
Castelino CB, Ball GF (2005): A role for norepinephrine in the regulation of context dependent ZENK expression in male zebra finches (Taeniopygia guttata). Eur J Neurosci 21: 1962-1972.

Chagnaud BP, Baker R, Bass AH (2011): Vocalization frequency and duration are coded in separate hindbrain nuclei. Nat Commun 2:346.

Creighton A, Satterfield D, Chu J (2013): Effects of dopamine agonists on calling behavior in the green tree frog, Hyla cinerea. Physiol Behav 116-117:54-59.

Curran-Everett D (2013): Explorations in statistics: the analysis of ratios and normalized data. Adv Physiol Educ 37:213-219.

Descarries L, Berube-Carriere N, Riad M, Bo GD, Mendez JA, Trudeau LE (2008): Glutamate in dopamine neurons: synaptic versus diffuse transmission. Brain Res Rev 58:290-302.

Devries MS, Cordes MA, Stevenson SA, Riters LV (2015): Differential relationships between $\mathrm{D}_{1}$ and $\mathrm{D}_{2}$ receptor expression in the medial preoptic nucleus and sexually-motivated song in male European starlings (Sturnus vulgaris). Neuroscience 301:289-297.

-Ericsson J, Stephenson-Jones M, Pérez-Fernández J, Robertson B, Silderberg G, Grillner S (2013): Dopamine differentially modulates the excitability of striatal neurons of the direct and indirect pathways in lamprey. J Neurosci 33:8045-8054.

Errchidi S, Moteau R, Hilaire G (1991): Noradrenergic modulation of the medullary respiratory rhythm generator in the newborn rat: an in vitro study. J Physiol 443:477-498.

Feng NY, Fergus DJ, Bass AH (2015): Neural transcriptome reveals molecular mechanisms for temporal control of vocalization across multiple timescales. BMC Genomics 16:408.

Fergus DJ, Bass AH (2013): Localization and divergent profiles of estrogen receptors and aromatase in the vocal and auditory networks of a fish with alternative mating tactics. J Comp Neurol 521:2850-2869.

Foran CM, Bass AH (1998): Preoptic AVT immunoreactive neurons of a teleost fish with alternative reproductive tactics. Gen Comp Endocrinol 111:271-282.

Forlano PM, Bass AH (2005): Steroid regulation of brain aromatase expression in glia: female preoptic and vocal motor nuclei. J Neurobiol 65:50-58.

Forlano PM, Deitcher DL, Bass AH (2005): Distribution of estrogen receptor alpha mRNA in the brain and inner ear of a vocal fish with comparisons to sites of aromatase expression. J Comp Neurol 483:91-113.

Forlano PM, Deitcher DL, Myers DA, Bass AH (2001): Anatomical distribution and cellular basis for high levels of aromatase activity in the brain of teleost fish: aromatase enzyme and mRNA expression identify glia as source. J Neurosci 21:8943-8955.

Forlano PM, Ghahramani ZN, Monestime CM, Kurochkin P, Chernenko A, Milkis D (2015): Catecholaminergic innervation of central and peripheral auditory circuitry varies with re- productive state in female midshipman fish, Porichthys notatus. PLoS One 10:e0121914.

Forlano PM, Kim SD, Krzyminska Z, and Sisneros JA (2014): Catecholaminergic connectivity to the inner ear, central auditory and vocal motor circuitry in the plainfin midshipman fish, Porichthys notatus. J Comp Neurol 522: 2887-2927.

Forlano PM, Marchaterre M, Deitcher DL, Bass AH (2010): Distribution of androgen receptor mRNA expression in vocal, auditory, and neuroendocrine circuits in a teleost fish. J Comp Neurol 518:493-512.

Genova RM, Marchaterre MA, Knapp R, Fergus D, Bass AH (2012): Glucocorticoid and androgen signaling pathways diverge between advertisement calling and non-calling fish. Horm Behav 62:426-432.

-Goebrecht GKE, Kowtoniuk RA, Kelly BG, Kittelberger JM (2014): Sexually dimorphic expression of tyrosine hydroxylase immunoreactivity in the brain of a vocal teleost fish (Porichthys notatus). J Chem Neuroanat 56:13-34.

-Gonzalez A, Smeets WJ (1991): Comparative analysis of dopamine and tyrosine hydroxylase immunoreactivities in the brain of two amphibians, the anuran Rana ridibunda and the urodele Pleurodeles waltlii. J Comp Neurol 303:457-477.

Goodson JL, Bass AH (2000): Forebrain peptides modulate sexually polymorphic vocal circuitry. Nature 403:769-772.

Goodson JL, Bass AH (2002): Vocal-acoustic circuitry and descending vocal pathways in a teleost fish: convergence with terrestrial vertebrates reveals conserved traits. J Comp Neurol 448:298-322.

-Grober MS, Fox SH, Laughlin C, Bass AH (1994): GnRH cell size and number in a teleost fish with two male reproductive morphs: sexual maturation, final sexual status and body size allometry. Brain Behav Evol 43:61-78.

Hara E, Kubikova L, Hessler NA, Jarvis ED (2007): Role of the midbrain dopaminergic system in modulation of vocal brain activation by social context. Eur J Neurosci 25:3406-3416.

Heimovics SA, Cornil CA, Ellis JMS, Ball GF, Riters LV (2011): Seasonal and individual variation in singing behavior correlates with $\alpha_{2}$ noradrenergic receptors in brain regions implicated in song, sexual, and social behavior. Neuroscience 182:133-143.

Heisler EK, Kittelberger JM (2012): Both $\mathrm{D}_{1}$ and $\mathrm{D}_{2}$-like receptors contribute to dopamine induced inhibition of vocal production in the midbrain periaqueductal gray of a teleost fish (conference abstract: Tenth International Congress of Neuroethology). Front Behav Neurosci DOI: 10.3389/conf.fnbeh.2012.27.00305.

Hökfelt T, Mårtensson R, Björklund A, Kleinau S, Goldsten M (1984): Distributional maps of tyrosine-hydroxylase-immunoreactive neurons in the rat brain; in Björklund A, Hökfelt $\mathrm{T}$ (eds): Handbook of Chemical Neuroanatomy. 1. Classical Transmitters in the CNS. Amsterdam, Elsevier, vol 2, pp 277-379.
Intrasexually Dimorphic Brain

Catecholamines in a Vocal Fish
Brain Behav Evol 2015:86:131-144 
-Jay M, DeFaveri F, McDearmid R (2015): Firing dynamics and modulatory actions of supraspinal dopaminergic neurons during zebrafish locomotor behavior. Curr Biol 25: $1-10$.

Kabelik D, Schrock SE, Ayres LC, Goodson JL (2011): Estrogenic regulation of dopaminergic neurons in the opportunistically breeding zebra finch. Gen Comp Endocrinol 173:96104.

Kaslin J, Panula P (2001): Comparative anatomy of the histaminergic and other aminergic systems in zebrafish (Danio rerio). J Comp Neurol 440:342-377.

Kelly AM, Goodson JL (2015): Functional interactions of dopamine cell groups reflect personality, sex, and social context in highly social finches. Behav Brain Res 280:101-112.

Kittelberger JM, Bass AH (2013): Vocal-motor and auditory connectivity of the midbrain periaqueductal gray in a teleost fish. J Comp Neurol 521:791-812.

Knapp R, Wingfield JC, Bass AH (1999): Steroid hormones and paternal care in the plainfin midshipman fish (Porichthys notatus). Horm Behav 35:81-89.

-LeBlanc MM, Good CT, MacDougall-Shackleton EA, Maney DL (2007): Estradiol modulates brainstem catecholaminergic cell groups and projections to the auditory forebrain in a female songbird. Brain Res 1171:93-103.

Ma PM (1997): Catecholaminergic systems in the zebrafish. 3. Organization and projection pattern of medullary dopaminergic and noradrenergic neurons. J Comp Neurol 381:411427.

Matragrano LL, LeBlanc MM, Chitrapu A, Blanton ZE, Maney DL (2013): Testosterone alters genomic responses to song and monoaminergic innervation of auditory areas in a seasonally breeding songbird. Dev Neurobiol 73: 455-468.

Matragrano LL, Sanford SE, Salvante KG, Sockman KW, Maney DL (2011): Estradiol-dependent catecholaminergic innervation of auditory areas in a seasonally breeding songbird. Eur J Neurosci 34:416-425.

- McIver EL, Marchaterre MA, Rice AN, Bass AH (2014): Novel underwater soundscape: acoustic repertoire of plainfin midshipman fish. J Exp Biol 217:2377-2389.
McLean DL, Fetcho JR (2004a): Ontogeny and innervation patterns of dopaminergic, noradrenergic, and serotonergic neurons in larval zebrafish. J Comp Neurol 480:38-56.

McLean DL, Fetcho JR (2004b): Relationship of tyrosine hydroxylase and serotonin immunoreactivity to sensorimotor circuitry in larval zebra fish. J Comp Neurol 480:57-71.

Mello CV, Pinaud R, Ribeiro S (1998): Noradrenergic system of the zebra finch brain: immunocytochemical study of dopamine-beta-hydroxylase. J Comp Neurol 400:207-228.

Miranda JA, Oliveira RF, Carniero LA, Santos RS, Grober ME (2003): Neurochemical correlates of male polymorphism and alternative reproductive tactics in the Azorean rock-pool blenny, Parablennius parvicornis. Gen Comp Endocrinol 132:183-189.

O'Connell LA, Hofmann HA (2011): The vertebrate mesolimbic reward system and social behavior network: a comparative synthesis. J Comp Neurol 519:3599-3639.

Parkis MA, Bayliss DA, Berger AJ (1995): Actions of norepinephrine on rat hypoglossal motoneurons. J Neurophysiol 74:1911-1919.

- Petersen CL, Timothy M, Kim SD, Bhandiwad AA, Mohr RA, Sisneros JA, Forlano PM (2013): Exposure to advertisement calls of reproductive competitors activates vocalacoustic and catecholaminergic neurons in the plainfin midshipman fish, Porichthys notatus. PLoS One 8:e70474.

Remage-Healey L, Bass AH (2007): Plasticity in brain sexuality is revealed by the rapid actions of steroid hormones. J Neurosci 27:1114-1122.

Rinaman L (2011): Hindbrain noradrenergic A2 neurons: diverse roles in autonomic, endocrine, cognitive, and behavioral functions. Am J Physiol Regul Integr Comp Physiol 300: 222-235.

Ringel LE, Basken JN, Grant LM, Ciucci MR (2013): Dopamine $\mathrm{D}_{1}$ and $\mathrm{D}_{2}$ receptor antagonism effects on rat ultrasonic vocalizations. Behav Brain Res 252:252-259.

Riters LV (2012): The role of motivation and reward neural systems in vocal communication in songbirds. Front Neuroendocrinol 33:194209.

Riters LV, Eens M, Pinxten R, Ball GF (2002): Seasonal changes in the densities of $\mathrm{a}_{2}-$ noradrenergic receptors are inversely related to changes in testosterone and the volumes of song control nuclei in male European starlings. J Comp Neurol 444:63-74.
Schlinger BA, Greco C, Bass AH (1999): Aromatase activity in the hindbrain vocal control region of a teleost fish: divergence among males with alternative reproductive tactics. Proc $\mathrm{R}$ Soc Lond B Biol Sci 266:131-136.

-Schweitzer J, Lohr H, Filippi A, Driever W (2012): Dopaminergic and noradrenergic circuit development in zebrafish. Dev Neurobiol 72: 256-268.

-Sisneros JA, Alderks PW, Leon K, Sniffen B (2009): Morphometric changes associated with the reproductive cycle and behaviour of the intertidal-nesting, male plainfin midshipman Porichthys notatus. J Fish Biol 74:18-36.

- Sisneros JA, Forlano PM, Knapp R, Bass AH (2004): Seasonal variation of steroid hormone levels in an intertidal-nesting fish, the vocal plainfin midshipman. Gen Comp Endocrinol 136:101-116.

Solis MM, Perkel DJ (2006): Noradrenergic modulation of activity in a vocal control nucleus in vitro. J Neurophysiol 95:2265-2276.

-Svensson E, Wikström MA, Hill RH, Grillner S (2003): Endogenous and exogenous dopamine presynaptically inhibits glutamatergic reticulospinal transmission via an action of $\mathrm{D}_{2}$-receptors on $\mathrm{N}$-type $\mathrm{Ca}^{2+}$ channels. Eur J Neurosci 17:447-454.

Tay TL, Ronneberger O, Ryu S, Nitschke R, Driever W (2011): Comprehensive catecholaminergic projectome analysis reveals singleneuron integration of zebrafish ascending and descending dopaminergic systems. Nat Commun 2:171.

Weltzien F, Pasqualini C, Sébert M, Vidal B, Belle NL, Kah O, Vernier P, Dufour S (2006): Androgen-dependent stimulation of brain dopaminergic systems in the female European eel (Anguilla anguilla). Endocrinology 147: 2964-2973.

Wilczynski W, Yang E, Simmons D (2003): Sex differences and hormone influences on tyrosine hydroxylase immunoreactive cells in the leopard frog. J Neurobiol 56:54-65.

Yamamoto K, Vernier P (2011): The evolution of dopamine systems in chordates. Front Neuroanat 5:21.

Zhao WS, Rui-Chen Q, Pilowsky G (2015): Catecholamine inputs to expiratory laryngeal motoneurons in rats. J Comp Neurol 523: 381-390. 